\section{Estetik}

Jurnal Bahasa Indonesia
Institut Agama Islam Negeri (IAIN) Curup, Indonesia

ISSN 2622-1810 (p); 2622-1829 (e)

volume 4, number 1, 2021 | page: 115-124

DOI: http://doi.org/10.29240/estetik.v4i1.2231

\title{
Analisis Tindak Tutur Direktif Novel Bumi Cinta Karya Habiburrahman El Shirazy
}

\author{
Rifa Dewi Zulaikha, Endang Rahmawati \\ Institut Agama Islam Negeri (IAIN) Surakarta, Indonesia \\ rifadewirdz@gmail.com
}

\begin{abstract}
This study discusses the directive acts of the novel Bumi Cinta by Habiburrahman El Shirazy and the directive acts of the directive acts of the novel Cinta Cinta by Habiburrahman El Shirazy. This type of research is a qualitative descriptive study. The theory used is the theory of Harun Joko Prayitno. The data source of this research is a speech in the novel Bumi Cinta by Habiburrahman El Shirazy. The research data consisted of utterances cited by directive speech acts which included directive speech acts and directive speech acts in the novel Bumi Cinta by Habiburrahman El Shirazy. Data were obtained by referring to the competent free engage listening technique obtained by note taking. The validity of the data in this study uses theory triangulation. Research results in the novel Bumi Cinta found six forms of directive speech acts, on request, request, invitation, approval, criticism and prohibition. When viewed, the directive speech function of the novel Bumi Cinta has a variety of functions. The form of directive speech acts requires the functions of ordering, commanding, asking, activating and letting. The form of directive speech acts requests, requests, hopes and offers. The form of speech act directive invitation has the function of inviting, persuading, supporting and asking. The form of directive speech acts to support the functions of advising, asking, asking and reminding. The form of directive speech acts of criticism has the function of reprimanding and winning. The form of directive speech acts have a ban function.
\end{abstract}

Keywords: Speech Acts, Directive, Novel

Abstrak. Penelitian ini membahas bentuk tindak tutur direktif novel Bumi Cinta karya Habiburrahman El Shirazy dan fungsi tindak tutur direktif novel Bumi Cinta karya Habiburrahman El Shirazy. Jenis penelitian ini adalah penelitian deskriptif kualitatif. Teori yang digunakan adalah teori dari Harun Joko Prayitno. Sumber data penelitian ini adalah tuturan dalam novel Bumi Cinta karya Habiburrahman El Shirazy. Data penelitiannya yaitu berupa tuturan yang memuat tindak tutur direktif yang mencakup bentuk tindak tutur direktif dan fungsi tindak tutur direktif dalam novel Bumi Cinta karya Habiburrahman El Shirazy. Data diperoleh dengan cara metode simak dengan teknik simak libat bebas cakap yang dilanjutkan dengan teknik catat. Keabsahan data pada penelitian ini menggunakan triangulasi teori. Hasil penelitian dalam novel Bumi Cinta ditemukan enam bentuk tindak tutur direktif, di antaranya: perintah, 
permintaan, ajakan, nasihat, kritikan, dan larangan. Jika dilihat, fungsi tindak tutur direktif novel Bumi Cinta mempunyai fungsi yang beragam. Bentuk tindak tutur direktif perintah mempunyai fungsi menyuruh, memerintah, mengharuskan, memaksa, dan menyilakan. Bentuk tindak tutur direktif permintaan mempunyai fungsi meminta, memohon, mengharap, dan menawarkan. Bentuk tindak tutur direktif ajakan mempunyai fungsi mengajak, membujuk, mendukung, dan mendesak. Bentuk tindak tutur direktif nasihat mempunyai fungsi menasihati, menganjurkan, menyarankan, dan mengingatkan. Bentuk tindak tutur direktif kritikan mempunyai fungsi menegur dan mengancam. Bentuk tindak tutur direktif larangan mempunyai fungsi melarang.

Kata Kunci: Tindak Tutur, Direktif, Novel

\section{Pendahuluan}

Manusia menggunakan bahasa untuk kebutuhan komunikasi sehari-hari. Manusia memakai ujaran-ujaran untuk mengemukakan apa yang ingin diutarakan. Oleh karenanya, manusia memerlukan perantara untuk memperkuat jalinan komunikasi, sebab komunikasi adalah alat untuk menyampaikan informasi.

Safrihady dan Mardikantoro (2017:60) menerangkan bahwa komunikasi adalah rangkaian tindakan yang menyatakan perasaan seseorang kepada orang lain. Komunikasi dapat terjadi jika ada kesaman pemikiran antara penutur dan mitra tutur. Komunikasi juga berkaitan dengan kemampuan memahami antara satu dengan lainnya. Melalui komunikasi maksud dan tujuan seseorang dapat dipahami oleh orang lain. Akan tetapi, jika seseorang tidak memahami maksud dari penutur maka akan terjadi permasalahan yang berselisih paham.

Komunikasi sejatinya adalah suatu cara penyampaian pesan baik ide maupun gagasan. Dalam berkomunikasi harus sesuai dengan konteks pembicaraan. Sama halnya dengan komunikasi, pragmatik juga tidak dapat dipisahkan dari konteks. Pragmatik mempelajari bahasa dan konteks secara bersamaan untuk mengetahui arti secara utuh. Konteks dapat menjadikan timbulnya dasar suatu percakapan. Konteks ujaran dalam keadaan santai akan berlainan dengan konteks ujaran saat situasi formal. Diksi yang digunakan waktu santai yaitu diksi sehari-hari, adapun diksi yang digunakan pada waktu resmi yaitu diksi yang baku. (Devina,2018:71). 
Pragmatik mengkaji mengenai bahasa dengan konteks. Pragmatik erat kaitannya dengan konteks, karena konteks merupakan bagian dari pragmatik. Menurut Saefudin (2013:2) dalam pragmatik yang paling penting adalah bahasa dapat diterima. Oleh karenanya kesamaan pemikiran dalam berkomunikasi sangatlah penting, agar dapat memahami konteks apa yang sedang dibicarakan. Komunikasi yang menetapkan tanggapan atau komentar disebut tuturan direktif, contohnya mengajak dan membujuk.

Perihal sudut pandang pendengar, maka bahasa mempunyai kedudukan sebagai direktif, yaitu macam tindak tutur yang bertujuan guna memberikan perintah kepada orang lain. Bahasa tidak hanya menimbulkan pendengar melakukan sesuatu, akan tetapi juga melaksanakan sesuai dengan apa yang diinginkan penutur.

Tindak tutur menurut Nadar (2009:20) terbagi menjadi dua, yaitu langsung dan tidak langsung. Tindak tutur langsung adalah apabila penutur memakai kalimat sesuai dengan modusnya. Adapun tindak tutur tidak langsung terjadi apabila penutur menggunakan modus tuturan tidak sesuai dengan konteks yang di ucapkan. (Wijana dan Muhammad Rohmadi, 2011:28)

Prayitno (2011:42) menyatakan tindak tutur direktif terdapat enam macam, yaitu perintah, permintaan, ajakan, nasihat, kritikan, dan larangan. Tindak tutur direktif memiliki fungsi yang beragam. Bentuk tindak tutur direktif perintah yakni, memerintah, menyuruh, mengharuskan, memaksa, meyilakan, dan meminjam. Bentuk tindak tutur direktif permintaan yakni, meminta, memohon mengharap, dan menawarkan. Bentuk tindak tutur direktif ajakan yakni membujuk, mengajak, merayu, mendorong, mendukung, menuntut, mendesak, menantang, menagih, dan menargetkan. Bentuk tindak tutur direktif nasihat, yakni menyerukan, menasihati, mengarahkan, menyarankan, menganjurkan, mengimbau, dan mengingatkan. Bentuk tindak tutur direktif kritikan yakni menyindir, menegur, mengumpat, mengancam, mengecam, dan marah. Bentuk tindak tutur direktif larangan yakni, melarang. 
Tindak tutur seperti Tolong buatkan omelet untukku!, selain dijumpai dalam komunikasi sehari-hari, juga ditemukan dalam kesusastraan, salah diantaranya yaitu novel. Hubungan antara tindak tutur sehari-hari dengan novel Bumi Cinta yaitu sebagai sarana penyampaian nasihat. Direktif nasihat lebih mendominasi daripada diektif lainnya, yakni ditemukan 60 data. Selain sebagai penyampaian nasihat, bahasa dalam novel Bumi Cinta bersifat lugas dan mudah dimengerti.

Novel menurut Sugihastuti dan Suharto (2015:43) merupakan buah pikir yang diatur dengan baik dan menjadi bagian yang utuh. Novel Bumi Cinta mengisahkan tokoh utama bernama Muhammad Ayyas yang melanjutkan studinya di Moskwa, Rusia. Selain mengisahkan tentang percintaan, novel Bumi Cinta juga mengisahkan perjuangan dalam berdakwah menyebarkan agama Islam di negara yang menganut paham kebebasan, seperti Rusia. Novel Bumi Cinta dipilih karena banyak memuat aspek religi.

Masalah yang diambil dalam pembahasan aspek religi adalah tentang sosok pemuda muslim yang berada di negara yang menganut paham kebebasan. Ditemukan persoalan yang berbeda dengan novel Habiburrahman El Shirazy lainnya, sebab di dalamnya memuat tuturan tindak tutur direktif yang berfungsi untuk penyampaian nasihat. Misalnya tuturan antara Yelena dengan Ayyas. Yelena menganggap adanya agama dan Tuhan membuat masalah, kemudian Ayyas menasihatinya, "Agama hadir justru untuk menyelesaikan berbagai masalah yang mendera umat manusia."

Habiburrahman El Shirazy adalah salah seorang yang berkecimpung di kesusastraan Indonesia. Ciri kepenulisan Habiburrahman El Shirazy adalah novel pembangun jiwa. Novel Habiburrahman El Shirazy didominasi dengan kisah Islami. Dari beberapa novel Habiburrahman El Shirazy, dipilih novel Bumi Cinta yang mewakili novel-novel lainnya. Novel dapat dijadikan sebagai sarana penyaluran nasihat. Peneliti menelaah ujaran dalam novel Bumi Cinta, lantaran didalamnya tidak sedikit ujaran direktif yang menarik untuk dikaji lebih lanjut. Banyaknya tuturan direktif yang ada dalam novel Bumi Cinta, maka peneliti tertarik untuk menganalisisnya. 
Penelitian yang relevan dengan penelitian ini adalah penelitian Teza (2019) mengkaji Tindak Tutur Direktif pada Novel Bidadaribidadari Surga Karya Tere Liye. Dakiroh (2017) mengkaji Tindak Tutur dalam Novel Api Tauhid Karya Habiburrahman El Shirazy. Hasil penelitiannya yaitu: Tindak Tutur Ilokusi dalam Novel Api Tauhid karya Habiburrahman El Shirazy meliputi representatif (menyatakan, meyakinkan, membual, mengeluh dan menyimpulkan ditemukan 26 tuturan), direktif (memesan, memerintah, memohon, mengemis, membela, mengundang, mengizinkan, menantang, dan menyarankan ditemukan 50 tuturan), komisif (berjanji, bersumpah, dan mengancam ditemukan 15 tuturan), ekspresif (berterima kasih, memberi selamat, meminta maaf, berbelasungkawa, menyesal, dan menyambut ditemukan 23 tuturan), deklarasi (mendefinisikan, menyingkat, menamai, memanggil, dan menganugerahi ditemukan 8 tuturan).

Persamaan dengan penelitian sebelumnya adalah sama-sama mengkaji mengenai bentuk tindak tutur direktif. Adapun perbedaannya terdapat pada objek kajian yang diteliti. Tindak Tutur Direktif dalam Novel Bumi Cinta Karya Habiburrahman El Shirazy pada bentuk dan fungsinya adalah telaah baru. Novel tersebut memiliki aspek religi.

Penelitian ini adalah penelitian kualitatif. Satori (2010:25) menyatakan penelitian kualitatif yaitu penelitian yang membahas keadaan sosial dengan melukiskan hal yang nyata. Ada dua macam data dalam penelitian ini, yaitu data utama dan data pendukung. Data utama merupakan data yang menjadi pokok persoalan, yaitu berupa tindak tutur direktif novel Bumi Cinta. Data utama berupa novel yang diterbitkan oleh penerbit Basmala Semarang, cetakan ke-1 (edisi revisi), November 2013 dengan ketebalan 546 halaman. Adapun data pendukung bersumber dari jurnal, buku dan internet yang dapat mendukung penelitian. Data pendukung berfungsi untuk melengkapi data utama.

\section{Hasil dan Pembahasan}

Terdapat dua masalah dalam penelitian yaitu bentuk dan fungsi tindak tutur direktif yang terdapat dalam novel Bumi Cinta karya Habiburrahman El Shirazy. Wujud tindak tutur direktif novel Bumi Cinta 
karya Habiburraman El Shirazy ditemukan enam macam, yaitu perintah, permintaan, ajakan, nasihat, kritikan dan larangan.

Peneliti menemukan 178 data yang memuat tindak tutur direktif pada novel Bumi Cinta. Data-data tersebut dijabarkan perintah ditemukan 25 data, yang meliputi: menyuruh 10 data, memerintah 5 data, mengharuskan 3 data, memaksa 1 data dan menyilakan 6 data. Direktif permintaan ditemukan 47 data, yang meliputi: meminta 31 data, memohon 3 data, mengharap 4 data dan menawarkan 9 data. Direktif ajakan ditemukan 25 data, yang meliputi: mengajak 14 data, membujuk 5 data, mendukung 1 data dan mendesak 5 data. Direktif nasihat ditemukan 60 data, yang meliputi menasihati 14 data, menganjurkan 5 data, menyarankan 20 data dan mengingatkan 21 data. Direktif kritikan ditemukan 20 data, yang meliputi: menegur 12 data dan mengancam 8 data. Adapun direktif larangan ditemukan 4 data.

Adapun fungsi tindak tutur direktif yang terdapat dalam novel Bumi Cinta karya Habiburrahman El Shirazy adalah sebagai berikut:

\section{Perintah}

Menurut Prayitno (2011:42) Perintah yaitu suatu ujaran yang bertujuan agar mitra tutur menyikapi atau mengerjakan sesuatu, seperti yang diujarkan penutur. Perintah dalam novel Bumi Cinta karya Habiburrahman El Shirazy ditemukan 25 data. Berikut contoh tindak tutur direktif yang dikutip dari novel Bumi Cinta karya Habiburrahman El Shirazy.

\section{"Tambah dua puluh dolar!"}

Konteks tuturan (BC/22) diujarkan seorang laki-laki berprofesi sebagai sopir taksi di Rusia. Penutur berumur lanjut usia (tidak muda lagi). Ujaran tersebut diujarkan penutur ketika ada di Golden Ring menggunakan nada kesal. Tujuan tuturan (BC/22) yaitu penutur menyuruh mitra tutur untuk menambah uang sopir taksi. Tuturan dituturkan dengan intonasi tinggi. Tuturan di atas termasuk tindak tutur direktif perintah yang ditandai oleh kata tambah dan tanda baca seru (!). 


\section{Permintaan}

Menurut Prayitno (2011:46) direktif permintaan yaitu ujaran yang dimaksudkan dengan harapan apa yang di kehendakkan penutur disanggupi mitra tutur. Permintaan dalam novel Bumi Cinta karya Habiburrahman El Shirazy ditemukan 47 macam. Berikut contoh tindak tutur direktif yang dikutip dari novel Bumi Cinta karya Habiburrahman El Shirazy (BC/41).

"Ya Allah, hamba minta kepada-Mu kebaikan daerah ini, kebaikan penghuninya, dan kebaikan yang ada di dalmnya. Dan hamba berlindung kepada-Mu ya Allah dari buruknya daerah ini dan keburukan yang ada di dalamnya"

Konteks tuturannya adalah seorang muslim yang taat pada agama, bernama Ayyas. Setelah salat Ayyas berdoa kepada Tuhannya (Allah) sebagaimana yang diajarkan oleh Rasulullah SAW. Ayyas meminta agar dijauhkan dari segala mara bahaya. Tuturan di atas termasuk tindak tutur direktif permintaan yang ditandai oleh kata minta.

\section{Ajakan}

Menurut Prayitno (2011:52) direktif ajakan yaitu ujaran yang memiliki tujuan dengan harapan mitra tutur turut mengerjakan apa yang diujarkan penutur. Jadi, ajakan sama artinya dengan penutur memberi perintah kepada mitra tuturnya, namun penutur sama halnya melakukan perbuatan tersebut. Ajakan dalam novel Bumi Cinta karya Habiburrahman El Shirazy ditemukan 25 macam. Berikut contoh tindak tutur direktif yang dikutip dari novel Bumi Cinta karya Habiburrahman El Shirazy (BC/29).

"Devid lalu mengajak Ayyas segera memasuki gedung apartemen tua yang dibangun zaman pemerintahan Stelin"

Konteks tuturannya (BC/29) adalah ketika Devid mencarikan tempat tinggal sementara untuk Ayyas. Devid mengajak Ayyas memasuki gedung apartemen tua yang berdiri dengan lima gedung bertingkat. Apartemen tersebut berlokasi di daerah strategi di tengah kota Moskwa. Tuturan di atas termasuk tindak tutur direktif ajakan yang ditandai oleh kata mengajak. 
4. Nasihat

Menurut Prayitno (2011:70) nasihat yaitu ketetapan yang memuat kesan baik penutur agar melakukan sesuatu. Nasihat dalam novel Bumi Cinta karya Habiburrahman El Shirazy ditemukan 60 macam. Berikut contoh tindak tutur direktif yang dikutip dari novel Bumi Cinta karya Habiburrahman El- Shirazy (BC/284).

"Ya berubahlah menjadi orang beriman Yelena"

Konteks tuturan (BC/284) dituturkan pada saat Ayyas bersama Bibi Margareta dan Yelena berada di rumah sakit. Tuturan di atas bermaksud memberi nasihat kepada Yelena untuk berubah dan menjadi orang beriman. Tuturan diujarkan dengan pengucapan sedang, menasihati dan membangun. Tuturan di atas termasuk tindak tutur direktif nasihat yang ditandai oleh kata berubahlah.

5. Kritikan

Prayitno (2011:75) menjelaskan direktif kritikan merupakan bagian bahasa yang bertujuan untuk menjadikan masukan sesuai perbuatan mitra tutur, atau dengan kata lain memiliki makna menyampaikan kritik kepada mitra tutur. Tuturan diujarkan dengan maksud mitra tutur mengerjakan atau melaksanakan sesuatu dengan lebih baik. Kritikan dalam novel Bumi Cinta karya Habiburrahman El Shirazy ditemukan 20 macam. Berikut contoh tindak tutur direktif yang dikutip dari novel Bumi Cinta karya Habiburrahman El Shirazy (BC/249).

"Kalau kau beriman, kau akan mudah minta bantuan. Yaitu minta bantuan kepada Tuhan Yang Maha Kuasa. Jika Tuhan membantu, tidak ada yang tidak terselesaikan"

Konteks tuturan $(\mathrm{BC} / 249)$ dituturkan pada saat Yelena meminta bantuan yang mengeluarkannya dari ketidaknyaman yang sedang dihadapinya. Tuturan diatas bermaksud memberi teguran (kritik) kepada Yelena. Tuturan di atas termasuk tindak tutur direktif kritikan yang ditandai oleh kata kalau.

6. Larangan

Menurut Prayitno (2011:63) direktif larangan memiliki maksud agar mitra tutur tidak diperkenankan atau dilarang mengerjakan sesuatu. 
Larangan pada tindak tutur direktif ditemukan 4 data. Berikut contoh tindak tutur direktif yang dikutip dari novel Bumi Cinta karya Habiburrahman El Shirazy (BC/31).

"Tenang, Sobat. Jangan marah dulu. Kita bawa barangmu ke atas. Nanti aku jelaskan semuanya"

Konteks tuturan (BC/31) dituturkan Devid pada saat Ayyas marah. Ayyas mengira, Devid menyengaja memperlakukan permainan dengan membayar uang sewa tempat tinggal satu apartemen dengan gadis bule yang katanya berdarah Finland. Tuturan dituturkan dengan intonasi nada tinggi, marah. Tuturan di atas termasuk tindak tutur direktif larangan yang ditandai oleh kata Jangan.

\section{Kesimpulan}

Berdasarkan penelitian di atas mengenai tindak tutur direktif novel Bumi Cinta karya Habiburraman El-Shirazy, maka dapat diambil kesimpulan bahwa, 1) wujud tindak tutur direktif novel Bumi Cinta karya Habiburraman El Shirazy ditemukan enam macam, yaitu perintah, permintaan, ajakan, nasihat, kritikan, dan larangan. Hasil penelitian tindak tutur direktif novel Bumi Cinta karya Habiburraman El-Shirazy di dominasi bentuk tindak tutur nasihat di temukan 60 data, 2) fungsi tindak tutur direktif novel Bumi Cinta karya Habiburraman El-Shirazy bermacam-macam. Peneliti menemukan 178 data yang memuat tindak tutur direktif pada novel Bumi Cinta.

\section{Bibliografi}

Dakiroh, Ikwatun. "Tindak Tutur Dalam Novel Api Tauhid Karya Habiburraman El Shirazy". Skripsi. Jakarta: Fakultas Ilmu Tarbiyah dan Keguruan, Universitas Islam Negeri Syarif Hidayatullah Jakarta. 2017.

Devina. 2018. "Tindak Tutur Ekspresif pada Anak-Anak Saat Bermain Bola di Lapangan" Ranah: Jurnal Kajian Bahasa, Vol. 1, No. 69 - 85. Bogor. Institut Pertanian Bogor.

Nadar. Pragmatik dan Penelitian Pragmatik. Yogyakarta: Graha Ilmu. 2009.

Prayitno, Harun Joko. Kesantunan Sosiopragmatik. Muhammadiyah University Press. 2011. 
Saefudin. "Pendekatan Pragmatik dalam Mendukung Kemampuan Komunikasi Lisan". Jurnal Al-Turas, Vol. 19, No. 1 (2013.)

Safrihady \& Mardikantoro, H. B. "Jenis dan Fungsi Pragmatis Tindak Tutur Masyarakat Melayu Dialek Sambas di Kota Singkawang". Jurnal Seloka, 59 - 67, (2017).

Satori, Djam'an, Aan Komariah. Metodologi Penelitian Kualitatif. Bandung: Alfabeta. 2010.

Sugihastuti dan Suharto. Kritik Sastra Feminis. Pustaka Pelajar. 2015.

Teza, Dian, Suryadi. 2019. "Tindak Tutur Direktif pada Novel Bidadaribidadari Surga Karya Tere Liye" Korpus: Jurnal Ilmiah , Vol. III, No. 1. Bengkulu. FKIP Universitas Bengkulu.

Wijana, I Dewa Putu dan Muhammad Rohmadi. Analisis Wacana Pragmatik Kajian Teori dan Analisis. Surakarta: Yuma Pustaka. 2011. 